\title{
Análise dos casos de sífilis congênita no município de Manhuaçu - MG
}

\author{
Monick Berbert-Morais, Emanuele Gama Dutra-Costa, Juliana Santiago-Silva
}

\begin{abstract}
Resumo
A sífilis em mulheres grávidas causa, com frequência, a sífilis congênita, doença com grande repercussão para a família e para a sociedade. Esta é resultado da disseminação da bactéria $\mathrm{T}$. pallidum da gestante infectada, não tratada ou tratada de forma desapropriada, para o bebê por via transplacentária. A doença permanece como um importante problema de saúde pública. No Brasil, estima-se que no ano de 2013 tenham ocorrido aproximadamente 21.382 casos de sífilis em gestantes, sendo $47 \%$ deles concentrados na região Sudeste. A cada ano mais casos de sífilis são registrados no município de Manhuaçu - MG. Em 2013 a taxa de detecção de sífilis em gestantes foi de 13,25\%, um número bem alto se comparado com 2007, onde não houve nenhum caso registrado da doença. Analisar os casos de sífilis congênita no município de Manhuaçu - MG, relacionando com os dados socioeconômicos das gestantes e as consequências apresentadas pelos recém-nascidos. Trata-se do estudo qualiquantitativo, onde foram verificados os casos de gestantes infectadas pela bactéria Treponema pallidum e os casos de evolução para sífilis congênita, entre os anos de 2010 a 2015. Foram encontrados 84 casos de sífilis em gestantes, dos quais 46 evoluíram para sífilis congênita. A maioria das gestantes analisadas apresentou baixa escolaridade e apenas 15 tiveram os respectivos parceiros tratados. A faixa etária das gestantes também mostra que a maioria dos casos atinge adolescentes e jovens que, porventura não possuem emprego formal. Ainda existem casos onde a gestante é diagnosticada apenas no momento do parto. Com o aumento dos casos, nota-se que a assistência pré-natal deve ser renovada.

Descritores: Gravidez; Sífilis em gestante; Cuidado pré-natal
\end{abstract}

